\title{
New Concepts for Water Well Screen Opening and Gravel Pack Size
}

\author{
Ahmed Babeker Elhag \\ Department of Civil Engineering, College of Engineering, King Khalid University, Abha, Saudi Arabia \\ Email address: \\ ahmedhydro@gmail.com, abalhaj@kku.edu.sa
}

To cite this article:

Ahmed Babeker Elhag. New Concepts for Water Well Screen Opening and Gravel Pack Size. American Journal of Water Science and Engineering. Vol. 6, No. 4, 2020, pp. 104-111. doi: 10.11648/j.ajwse.20200604.11

Received: September 16, 2020; Accepted: October 12, 2020; Published: October 30, 2020

\begin{abstract}
The purpose of the study to obtained well screens opening size and gravel packs size, and to access within the groundwater inter through the aquifer to the well screen and prevent running sand from entering the well. The use of properly designed screen and gravels are important and this paper is an important reference for the design of groundwater wells. In this study, the purpose of the circle method is to design water well and the benefits of sand control. The determination of screen slot size and its variation in the opening is often a major aim of hydrogeological studies. However, measurement of hydraulic conductivity $(\mathrm{K})$ at a high spatial resolution in sedimentary aquifers is a challenge. One commonly used approach is to estimate slot size from grain size analysis. The objectives of this study are to compare between curve of grain size analysis, bar graph and circle method used applied different formulas for the determination of slot size from grain-size data and to evaluate how well this method predicts slot size and gravel pack. Correlation between the mechanical analysis curve, bar graph and the circle methods were found for the used applied different formulas. Based on circle results, the applied circle formulas appear to be suitable for an initial assessment of aquifer properties. However, considering the difference in calculated aquifer parameter values, results are smaller significantly and reliable for the high analysis of aquifer materials.
\end{abstract}

Keywords: New Concept, Sieve Analysis, Grain Size Distribution, Bar Graph and Circle Diagram, Aquifer Materials

\section{Introduction}

A quantitative description of soil particle size distribution (PSD) is important for soil structure research (Yusong Deng, et al. 2017) [17]. During the last few decades, several different methods have been established for determining soil PSD (Birkhofer, et. al. 2012, Skaggs, et. Al. 2001, and Buchan, et. Al. 1993) [2, 14, 3]. Textural analysis is commonly used to characterize soil PSD, but the size definitions of the three main particle fractions (sand, silt and clay) are rather arbitrary and thus cannot provide complete information about the soil PSD.

The process of designing groundwater wells requires fixing a certain special type of screens so that they correspond to the layer carrying the groundwater. There are a number of factors that controlling the choice of the quality of screens, the most important of which are the nature of the aquifer, the quality of the groundwater, the depths of wells and vertical and horizontal pressures. Generally, screens differ in the size of the openings (slot size) and the materials that are made of them. The good materials of screens are the ones that give a high efficiency and a longer life for operation and therefore the best openings (slot size) as possible to provide the maximum open area in front of the aquifer and with the requirements of hardness and strength. The proper selection of slot opening in relation to the sizes of aquifer materials (Mehaysen, and Mahasneh, 2015) [11].

The size of the screen opening in most types of geological formations varies depending mainly on the nature of the geological formation and the development of the aquifer or artificial gravel pack. When naturally developing water wells, the size of the screen opening (slot size) is chosen based on the graduation of the sizes of the grains samples representing the water producing layer that is obtained through the results of the sieve analysis (Figure 1) by maintaining and remaining. The aquifer materials retained about $40 \%$ and allowing $60 \%$ to pass through the screen during the well pumping and development process. But if the size of the slot size of the screen is large oversized greater than recommended, then the screen definitely enter the components of the fine aquifer 
materials are inside the well and thus it becomes very difficult to clean the well water from those sands. On the other hand, if the size of the screen opening is smaller than the size recommended, in this case, water flow is more decrease in the well, and as a result, there is more decline in the water level, it is called more head loss, in addition to corrosion of well filters because of this resistance. The amount of slot size in the screen should not exceed $30-40 \%$ of the surface area of the screen in order to maintain a low speed for entering the water to the screen about $(0.03 \mathrm{~m} / \mathrm{sec})$ or less, where the friction between water and the slot size in the screen at this speed is negligible.

Objective of the study:

The goal of designing the well screen and gravel pack size is to maintain the guarantee of entering the groundwater of the well and preventing the entry of sand, after the completion of the well development process.

The aim of this study, in general, is to find a new system by avoiding the negatives and errors of the old method. In detail, this study serves and determines the size of the screen opening and gravel depending on extracting the bar graph and angle values from the circle model.

The main purpose of dry sieve analysis is perform to distinguish between different grain sizes of aquifer materials samples were collected and extracted from holes during well drilling project. From the laboratory, the samples were treated and tested for grain size distribution according to the standard procedures (Justine, 2007) [10]; furthermore, the grain size distribution was determined using the standard sieving technique as described by the American Society of Testing and Materials (ASTM) (1995), and (Tanner and Balsillie, 1995) [15].

The gravel pack surrounding the well screen may be provided in two ways (E. E. Johnson, 1955) [9]. A naturally developed filter pack is produce by removing the fine sand and silt from the aquifer material, bringing these fines through the well screen openings by surging and bailing.

For the naturally developed filter pack, the choosing of the correct size of screen openings permits the development of the pack from the aquifer material at some distance outside the face of the screen [8] (3).

\section{Material and Methods}

Nur Aqilah Ahad and et al. (2019) [12] suggested sand retention tests are commonly used to select the most appropriate screen to be used in sand control. Particle size techniques that are commonly used for classification of aquifer materials, estimate slot openings of a screen and diameter of artificial gravel pack. In a dry sieve analysis, Particle size distribution of sand is determine by the mechanical separation of particles. Gravel and sand particles are first separated into individual grains and then cleaned, dried, and weighed. They are then pass through a set of sieves in a shaker, with the coarsest sieve at the top and finest sieve at the bottom. Typically, the smallest sieve that is used in the dry sieve is $400 \mathrm{US}$ mesh $(37 \mathrm{~lm})$. Sand particles that pass through the smallest sieve are collect in a pan. From the weight of the particles retained in each individual sieve, cumulative weight retained percent by each sieve size is calculated and plotted against sieve size on a semilogarithmic scale (Figures 2, 3 and 4). In a recent study plotting the cumulative weight retained or passing angle by each sieve size against grain size (Figure 5) (Elhag, 2017) [5].

\subsection{Well Screen Slot Openings}

The selection of the screen slot sizes is based upon the aquifer or the filter pack material grain size distribution (Akulshin, et al. 2019) [1]. The slotted sizes have been used to provide sand control in much water well, sometimes fine slots clogged by small sand and silt particles. Theoretically, the slot size should be as wide as possible. The width of these slots is normally made as small as mechanically practical so that they will retain a large fraction of the formation and as much as possible (Ehsan Khamehchi, et al, 2014) [4]. In practice, the values of slot opening vary from low as $0.2 \mathrm{~mm}$ to large as $5 \mathrm{~mm}$.

The shape of slot openings is different shaped wire, which is carefully slot (wound) so that there is a continuous gap between wires. The shape of slot size in horizontal and vertical formers placed around the internal diameter of the screen. Wire wrapped screens have the advantage over a slotted liner that the gap between the wires can be made smaller and be held to the target value with a much greater accuracy; allowing the screen to retain finer-grained formations than the slotted liner (Okoye, et al. 1992) [13].

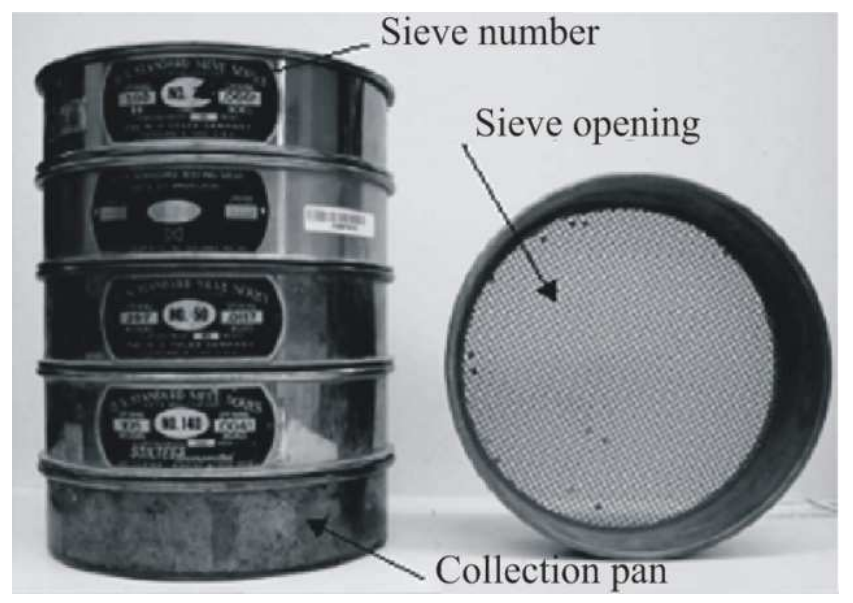

Figure 1. A set of standard sieves are suitable for the classification of loose sediments of various sizes.

Screen openings are determined based on the nature of the aquifer and the sizes of the formation granules that are mechanically analyzed in the laboratory (Figure 1). After drawing the sample curve from plotting the values of the sieve opening on the basis of the granular size on the horizontal axis and the corresponding percentage of the cumulative remained weights or cumulative pass by vertically on semi-log paper (Figure 2). To choose the appropriate aperture size for the well screen, the point is chosen on the percentage of the cumulative retained weight 
ratio curve that intersects the horizontal line $40-50$ percent on the vertical axis for the purpose of retaining fine and homogenous composition materials, or the corresponding size of the ratio may be chosen between 30 - 50 percent to reserve the coarse grained composition. Generally, we find that the diameter of the slot size ranges between $1-6 \mathrm{~mm}$.

\subsection{Gravel Pack}

Very important to study gravel pack size, because the fine sand is penetration water bearing formation and clogging screen opening. The pack material should be placed continuously, but slowly, to avoid bridging and sorting of the particles. If the screen is not centered in the bore hole and is in direct contact with the formation material (no gravel pack between the well screen and formation), sand pumping will result. These parameters directly influence gravel pack permeability and consequently affect water production rate. The size of gravel is chosen by sieve analysis. In practice, the size of gravel pack reaches about five times than the slot size, and according to (Ehsan Khamehchi, et al, 2014) [4] gravel pack is chosen by properties available.

Gravel pack surrounding the well screen is divided into two types, artificial and natural packs. Artificial gravel increasing the permeability area around the well screen by removing the fine formation material. To ensure that the gravel surround the screen. It is recommended that the gravel range from 3 to 8 inches thick. This thick will successfully hold most of the formation particles while allowing water to pass and enter the screen through the slot sizes.

The important materials of gravel packaging including well rounded granules shape, clean and consist of silicon (quartz) instead of limestone that should be limited to less than 5 percent.

\subsection{Firstly Bar Graph Procedure}

This method differs in its idea from the circle method in terms of application conditions and shape, but it gives the same results, and from this method it is possible to obtain a vertical-shaped diagram through which it is possible to distinguish the sizes of the most dominant particles in the aquifer, and to apply them we follow the following steps:

Vertically, plot the percentages of each of the cumulative retained weight or the cumulative passing weight versus the values of the size of the sieve opening on an arithmetic or semi-logarithmic scale (Figures 3 and 4).

Extract the values of the screen opening size, effective size and uniformity coefficient directly from the bar graph (Figure 4).

\subsection{Secondly Circle Experimental Procedure}

The application of the circle method differs from the curve of grain size distribution. The most important features of this new method, its gives a clear idea of the most prevalent granular types in the aquifer through the value of the angle concerned in the (Figure 3), and the circle method is applied by the following steps:
Extract the value of the angle for each of the cumulated weight remained or passing through for each sieve separately, where the largest angle shows the value of the dominant type of geological formation, table 3 and figure 5 .

Calculate the angle value of the retained weight of each sieve by multiplying the value of the retained weight of each individual sieve by $\left(360^{\circ}\right)$, and dividing by the total weight of the sample by using the following formula:

$$
A_{v}=\frac{W_{r}}{W_{t}} \times 360^{\circ}
$$

Where,

$A_{v}=$ the angle value of retained on each sieve.

$W_{r}=$ the weight retained on each sieve $(\mathrm{g})$.

$W_{t}=$ the total weight of sample $(\mathrm{g})$.

Extract the angle value of the cumulative passing weight by subtracting the total value of the circle $\left(360^{\circ}\right)$ from the angle value of the cumulative retained weight.

The value of the cumulative weight angle remained is calculated in a clockwise direction while the value of the cumulative weight angle passing is found in the opposite direction of the clock.

Find the value of the sieve opening size (grain size) from the circle, which is calculated from the sum of the cumulative angle values starting from the angle equal $360^{\circ}$, and after applying the following equation:

$$
\text { Slot size }\left(d_{50}\right)=360^{\circ} \times 0.5
$$

Find the value of the effective size $\left(d_{10}\right)$ of the cumulative weight passing and $\left(d_{90}\right)$ of the cumulative weight of retained. The effective size of a granular soil is a good measure to estimate the hydraulic conductivity $(K)$ and drainage through soil.

Extract the value of the uniformity coefficient $\left(U_{c}\right)$ of the cumulative weight passing and retained respectively, when applying the following mathematical equations:

$$
U_{c}=\frac{d_{60}(40 \% \text { retained })}{d_{10}(90 \% \text { retained })}
$$

\section{Result and Discussion}

Sieving is the most basic of the particle sizing techniques. It consists of having the sediment pass through (by agitation) a series of stacked sieve meshes with defined opening sizes (Gloria, 2017) [6]. The new technique of sieving and the analysis of the result are simple, because it has given a clear idea of the most granular types of geological formation through the value of the angle in the different size.

The analysis of circle method is perform by using the values of angle, but the curves of mechanical analysis are performed by using the cumulative weight of particles retained or passing percent. Thus, it could be said that the difference between two analyses results are insignificant.

The results of the sieve analysis should be use for the best design for slot size and uniformity package of materials (table 1). 
Table 1. Shows the uniformity coefficient of formation can be divide into three groups (Source: Yanlong, et al. 2017) [16]

\begin{tabular}{ll}
\hline Uniformity of sand & $U_{c}$ \\
Uniform & $\leq 5$ \\
Non-uniform & $5<U_{c} \leq 8$ \\
Extremely non-uniform & $U_{c}>8$ \\
\hline
\end{tabular}

The general rule is that at least 90 percent of the gravel pack should be retain where the pack and aquifer are uniform; however, values as low as 40 percent have been suggested if there is bad uniformity (Johnson, 1975) [7].
Example 1:

The results of sieve analysis test carried out on a $500 \mathrm{~g}$ sample of underground aquifer, proposed to be tap for installation of a tube-well, is given in the table below (Groundwater Hydrology and Construction of Wells and Tube-wells). Using the information table 2, computing the items as the following:

1. Slot size of the screen.

2. Effective size.

3. Uniformity coefficient.

Table 2. The results of the design of well.

\begin{tabular}{|c|c|c|c|c|}
\hline Slot size (mm) & Weight of retained (g) & Cu.W.R. (g) & Cu.W.R. \% & Cu.W.P. \% \\
\hline 2.54 & 0.0 & 0.0 & 0.0 & 100 \\
\hline 1.80 & 6 & 6 & 1.2 & 98.8 \\
\hline 0.30 & 15 & 21 & 4.2 & 95.8 \\
\hline 0.25 & 320 & 341 & 68.2 & 31.8 \\
\hline 0.21 & 5 & 346 & 69.2 & 30.8 \\
\hline 0.12 & 34 & 430 & 86.0 & 14.0 \\
\hline$<0.12$ & 70 & 500 & 100 & 0.0 \\
\hline$\sum$ & 500 & & & \\
\hline
\end{tabular}

Cu. W. R\%=Cumulative weight retained percent.

$\mathrm{Cu}$. W.P\%=Cumulative weight passing percent.

The distribution curve of sieve analysis data is plotted between grain size in $\mathrm{mm}$ horizontal against cumulative weight passing (finer) percent vertical, as shown in figure below.

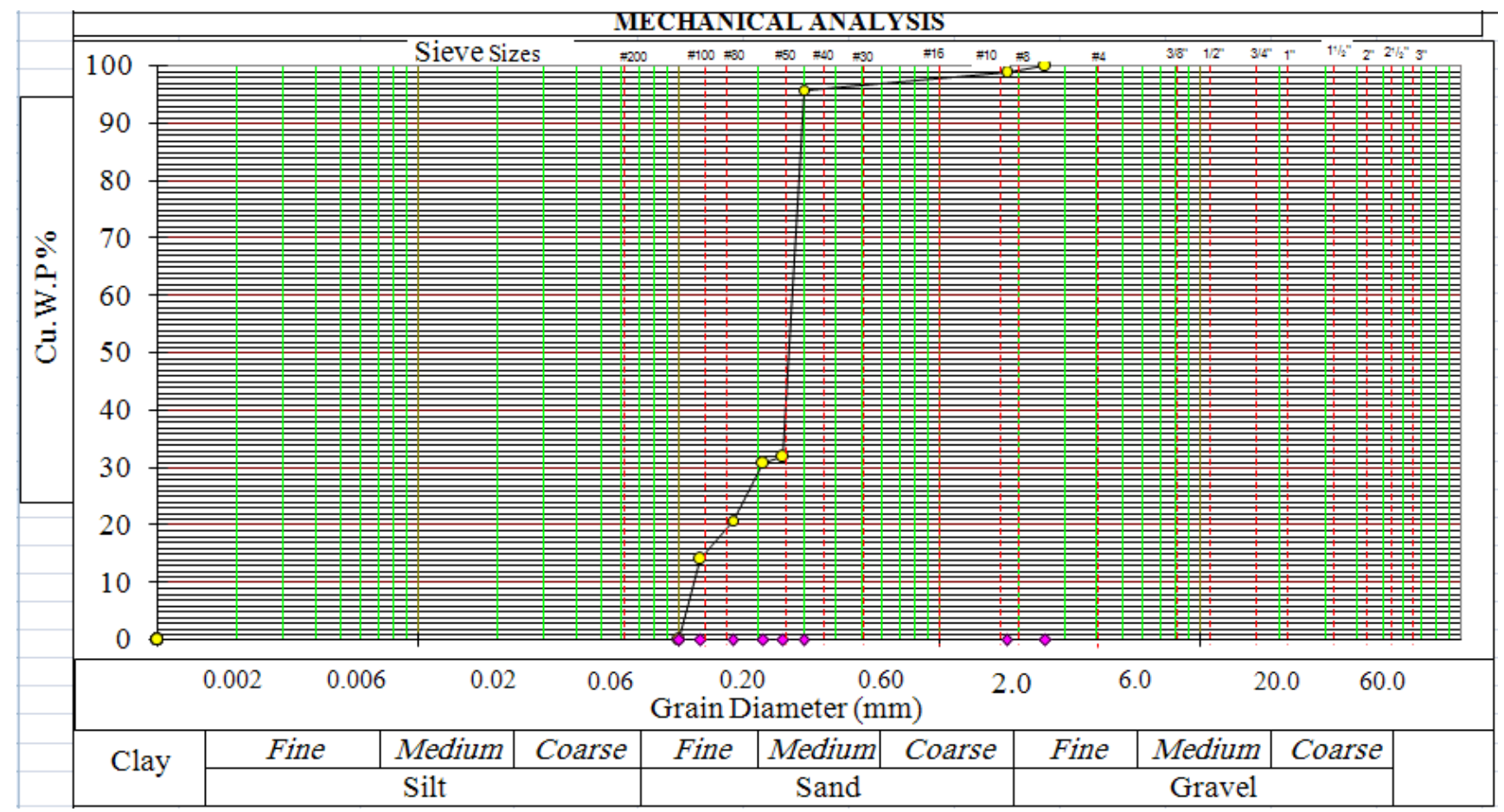

Figure 2. Shows the curve of grain size distribution for the aquifer materials.

The given sieve analysis data is analyzed, as shown in table 2 distribution curve is then plotted between grain size in $\mathrm{mm}$ (on $\log \mathrm{x}$-axis) and \% age finer (on y-axis), as shown in (Figure 2).
Solution:

The bar diagram data is plotted between grain size in $\mathrm{mm}$ against percentages of each of the cumulative retained weight and the cumulative passing weight, as shown in figure below. 


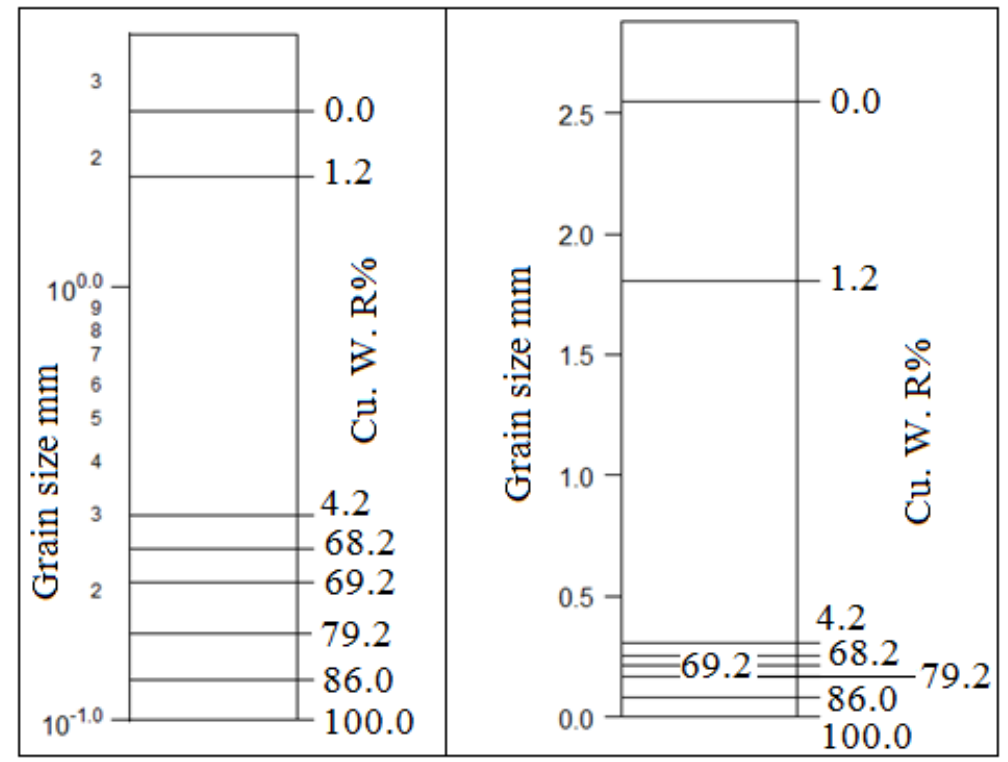

Figure 3. Shows the percentages of the cumulative retained weight versus the sieve size (diameter of the particles) vertically, on a semi-logarithmic scale, and on a mathematical scale respectively.

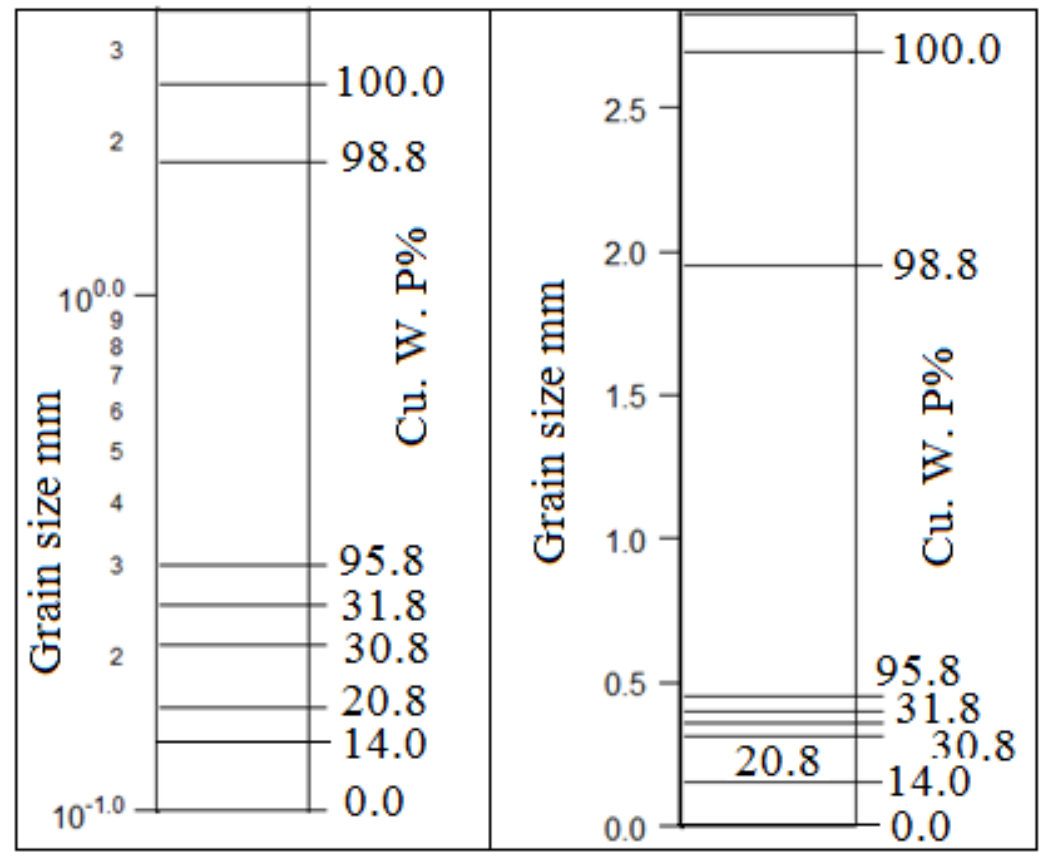

Figure 4. Shows the percentages of the cumulative passing weight versus the sieve size vertically, on a semi-logarithmic scale, and on a mathematical scale respectively.

Firstly: the method of the cumulative retained weight percent:

The size of the screen opening

$$
\text { - Slot size } d_{50}=50 \%=0.26 \mathrm{~mm}
$$

The gravel pack size is five times the size of the screen opening.

$$
\begin{gathered}
- \text { Gravel pack size }=5 \times 0.26=1.3 \mathrm{~mm} \\
- \text { Effective size }=d_{90}=90 \%=0.102 \mathrm{~mm}
\end{gathered}
$$

Uniformity coefficient $\left(U_{c}\right)$

$$
\begin{gathered}
d_{40}=40 \%=0.27 \mathrm{~mm} \\
U_{c}=\frac{d_{40}}{d_{90}}=\frac{0.27}{0.102}=2.65
\end{gathered}
$$

Secondly: the method of the cumulative passing weight percent:

The size of the screen opening

$$
\text { - Slot size } d_{50}=50 \%=0.26 \mathrm{~mm}
$$


The gravel pack size is five times the size of the screen opening.

$$
\begin{gathered}
- \text { Gravel pack size }=5 \times 0.26=1.3 \mathrm{~mm} \\
- \text { Effective size }=d_{10}=10 \%=0.102 \mathrm{~mm}
\end{gathered}
$$

Uniformity coefficient $\left(U_{c}\right)$

$$
\begin{gathered}
d_{60}=60 \%=0.27 \mathrm{~mm} \\
U_{c}=\frac{d_{60}}{d_{10}}=\frac{0.27}{0.102}=2.65
\end{gathered}
$$

Example 2:

Based on the data in the table 3, calculate the following:

1. Slot size of the screen.

2. Effective size.

3. Uniformity coefficient.

Solution:

The given sieve analysis data is analyzed, as shown in table 3 distribution circle is then plotted depending on the grain size in $\mathrm{mm}$ and angles of retained and finer, as shown in (Figure 5).

Table 3. The results of the design of well.

\begin{tabular}{llllll}
\hline Slot size (mm) & Weight of retained $(\mathbf{g})$ & Cu.W.R. $(\mathrm{g})$ & Value of angle & Cu. W. R values of angles & Cu. W. P values of angles \\
\hline 2.54 & 0 & 0 & $0.0^{\circ}$ & $0.0^{\circ}$ & $360.0^{\circ}$ \\
1.80 & 6 & 6 & $4.3^{\circ}$ & $4.3^{\circ}$ & $355.7^{\circ}$ \\
0.30 & 15 & 21 & $10.8^{\circ}$ & $15.1^{\circ}$ & $344.9^{\circ}$ \\
0.25 & 320 & 341 & $230.4^{\circ}$ & $245.5^{\circ}$ & $114.5^{\circ}$ \\
0.21 & 5 & 346 & $3.6^{\circ}$ & $249.1^{\circ}$ & $110.9^{\circ}$ \\
0.16 & 50 & 396 & $36.0^{\circ}$ & $285.1^{\circ}$ & $74.9^{\circ}$ \\
0.12 & 34 & 430 & $24.5^{\circ}$ & $309.6^{\circ}$ & $50.4^{\circ}$ \\
$<0.12$ & 70 & 500 & $50.4^{\circ}$ & $360.0^{\circ}$ & $0.0^{\circ}$ \\
$\Sigma$ & 500 & & & & \\
\hline
\end{tabular}

$\mathrm{Cu}$. W. $\mathrm{R}=$ Cumulative weight of retained.

$\mathrm{Cu}$. W.P=Cumulative weight of passing.

Firstly:

Design the size of the slot size for the slotted screen pipes, gravel pack, and the aquifer materials depending on cumulative value of passing angles (Table 3) as follows:

Slot size of the screen calculated depending on cumulative values of passing angles.

$$
\text { Slot size }\left(d_{50}\right)=360^{\circ} \times 0.5=180^{\circ}=0.26 \mathrm{~mm}
$$

The diameter or size of the gravel pack is five times the size of the screen opening.

$$
5 x d_{50}=5 x 0.26=1.3 \mathrm{~mm}
$$

Effective size:

The effective size $d_{10}$ is define as the sieve size passing $10 \%$ of the fine particles and $90 \%$ of the coarser aquifer materials are retained.

$$
\mathrm{d}_{10}=360^{\circ} \times 0.1=36^{\circ}=0.102 \mathrm{~mm}
$$

Uniformity coefficient:

The uniformity coefficient $U_{c}$ is that ratio of the sieve size passing $60 \%$ of the particles; to the sieve size passing $10 \%$ are retained. $40 \%$ of the aquifer materials are retained, because it's coarser than the sieve size passing $60 \%$.

$$
\begin{gathered}
\mathrm{d}_{60}=360^{\circ} \times 0.6=216^{\circ}=0.27 \mathrm{~mm} \\
U_{c}=\frac{d_{60}}{d_{10}}=\frac{0.27}{0.102}=2.65
\end{gathered}
$$

Secondly:

According to sieve analysis data (Table 3) easy to applied the circle method and calculate the characteristics of the aquifer materials depending on cumulative weight value of retained angles as follows:

Slot size of the screen and gravel pack calculated depending on cumulative values of retained angles.

$$
\text { Slot size }\left(d_{50}\right)=360^{\circ} \times 0.5=180^{\circ}=0.26 \mathrm{~mm}
$$

Gravel pack

$$
5 x d_{50}=5 x 0.26=1.3 \mathrm{~mm}
$$

Effective size:

$$
d_{90}=360^{\circ} \times 0.9=324^{\circ}=0.102 \mathrm{~mm}
$$

Uniformity coefficient:

$$
\begin{gathered}
\mathrm{d}_{40}=360^{\circ} \times 0.4=144^{\circ}=0.27 \mathrm{~mm} \\
U_{c}=\frac{d_{40}}{d_{90}}=\frac{0.27}{0.102}=2.65
\end{gathered}
$$

Overall results showed that the aquifer parameters for sand samples are available for circle method because the formula is suitable for different grain sand.

\section{Conclusion}

The aim of this study was to compare between the grain size analysis curve and circle diagram. The formulas of different methods approach to represent the slot size, effective size and uniformity coefficient values of grain size data is a suitable method. 

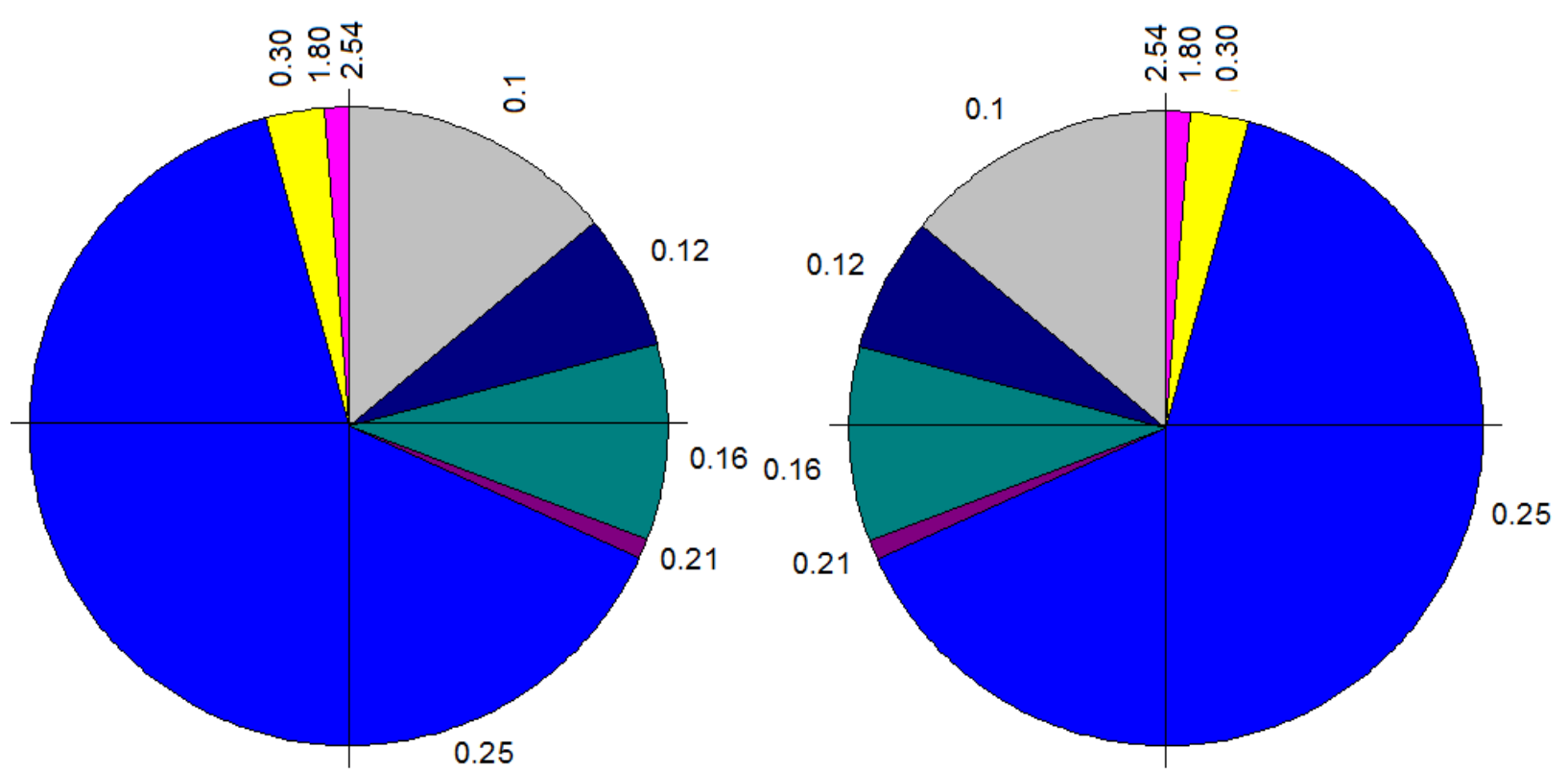

Figure 5. The value of the angle and the size of sieve slot in millimeters are show for all types of granules of different sizes for the clockwise direction and counterclockwise respectively.

The slot sizes are determined based on the nature of the aquifer materials and the sizes of the water bearing formation grains are analyze mechanically. This is followed by drawing a circle diagram representing the sample of the aquifer by plotting the values of the sieve opening (grain size) versus the cumulative remained weights or the cumulative passing weight in a circle $\left(360^{\circ}\right)$ degree.

The results of circle method is the reliability for determination of aquifer measured aquifer parameter values of grain size distribution and to evaluate how well this method employs a support values similar to that of the grain size analysis curve. A high correlation between grain size distribution curve and circle method could be show for most of the applied formulas. Finally, the new circle method is distinguish from the old method in that it shows the dominant grains in the geological formation through the largest angle in the general shape of the circle.

Based on the grain size analysis and results, the following conclusions can be including:

a) For the studied sample showed a wide range of aquifer material types, the best overall estimation of aquifer parameter and well design are reach based on circle method.

b) Circle diagram is very sensitive to shape of the grading aquifer materials.

c) Circle method is very suitable for the estimation of the slot size, effective size and uniformity coefficient in this study in comparison to the curve of grain size analysis.

\section{Acknowledgements}

The author would like to thank King Khalid University, Department of Civil Engineering for giving me the opportunity for doing all tests on laboratory and their help and support during fieldwork.

\section{References}

[1] Akulshin, A. A V I Shcherbakov, V. I. and Uchaev A. S. (2019): Selection of well screen parameters as aspect of water well design. International Conference on Construction, Architecture and Technosphere Safety. Available from: https://www.researchgate.net/publication/337871655_Selectio $\mathrm{n}$ of_well_screen_parameters_as_aspect_of_water_well_desi gn [accessed Sep 30 2020].

[2] Birkhofer K, Scho"ning I, Alt F, Herold N, Klarner B, Maraun M, et al. (2012): General relationships between abiotic soil properties and soil biota across spatial scales and different land-use types. Plos One.; 7: 1-8.

[3] Buchan G. D, Grewal K. S, Robson A. B. (1993): Improved models of particle size distribution: an illustration of model comparison techniques. Soil Sci. Soc. Am. J.; 57: 901-908.

[4] Ehsan Khamehchi, Omid Ameri, and Ali Alizadeh (2014): Choosing an optimum sand control method. Faculty of the Petroleum Engineering, Amirkabir University of Technology, Tehran, Iran. Egyptian Petroleum Research Institute, Egyptian Journal of Petroleum. www.elsevier.com/locate/egyjp. www.sciencedirect.com.

[5] Elhag, A. B (2017): New Novel for Construction of Water Well Design, Journal of Hydrogeology and Hydrologic Engineering, $\quad$ Vol: $\quad 6 \quad$ Issue: 2, https://www.scitechnol.com/peer-review/new-novel-usefulfor-construction-of-water-well-designUBsH.php?article_id=6529.

[6] Gloria I. López (2017): Grain size analysis. Encyclopedia of Earth Science Series Encyclopedia of Geoarchaeology Allan S. Gilbert (Volume Ed.) Springer. pp. 341-348.

[7] Johnson, D. (1975): Selection of screen slot size for uniform sand. 
[8] Johnson, E. E (1959): The principles and practical methods of developing water wells. Bull. 1033 (rev.). St. Paul, MN.

[9] Johnson, E. E (1955): Judging proper gravel-pack thickness: Johnson Natl. Drillers' Jour., V. 27. No. 2, p. 1-4.

[10] Justine Odong (2007): Evaluation of Empirical Formulae for Determination of Hydraulic Conductivity based on Grain-Size Analysis. Journal of American Science, 3 (3), School of Environmental Studies, China University of Geosciences, 388 Lumo Road, Wuchang, Wuhan, Hubei, P. R. China.

[11] Mehaysen, and Mahasneh (2015): Well Screens and Gravel Packs. Global Journal of Researches in Engineering: $\mathrm{j}$ General Engineering Volume 15 Issue 5 Version 1.0, Online ISSN: 2249-4596 Print ISSN: 0975-5861 (USA).

[12] Nur Aqilah Ahad, Morteza Jami, and Stephen Tyson (2019): A review of experimental studies on sand screen selection for unconsolidated sandstone reservoirs. Journal of Petroleum Exploration and Production Technology https://doi.org/10.1007/s13202-019-00826-y.

[13] Okoye, C. U. Suriyakriangkai, S. Ghalambor, A (1992): Analysis of skins and the performance of gravel packed completions in oil and gas wells, SPE 23827, In: SPE Symposium or Formation Damage Control Held in Lafayette, Louisiana, 1992.
[14] Skaggs T. H, Arya L. M, Shouse P. J, Mohanty B. P. (2001): Estimating particle-size distribution from limited soil texture data. Soil Sci. Soc. Am. J. 2001; 65: 1038-1044.

[15] Tanner, W. F. and Balsillie, J. H. (1995): Environmental clastic granulometry; Florida geological survey special publication 40; Florida geological survey; Tallahassee, FL, USA.

[16] Yanlong, L. I, Gaowei, H. U, Changling, L. I. U, Nengyou, W. U, CHEN Qiang, Lele, L. I. U, and Chengfeng, L. I (2017): Gravel sizing method for sand control packing in hydrate production test wells. Cite this article as: Petroleum Exploration and Development, 2017, 44 (6): 1016-1021. Available on line at www.Sciencedirect.com. Availablefrom:https://www.researchgate.net/publication/3215 84052_Gravel_sizing_method_for_sand_control_packing_in hydrate_production_test_wells [accessed Sep 15 2020].

[17] Yusong Deng, Chongfa Cai, Dong Xia, Shuwen Ding, and Jiazhou Chen (2017): Fractal features of soil particle size distribution under different land-use patterns in the alluvial fans of collapsing gullies in the hilly granitic region of southern China. PLoS ONE 12 (3): e0173555. https://doi.org/10.1371/journal. pone.0173555. 